\title{
Chronically Exposed Knee Hardware
}

Alyson Dobracki, DO

From Main Line Health at Bryn

Mawr Hospital in

Pennsylvania

Financial Disclosures:

None reported.

Support: None reported.

Address correspondence to Alyson Dobracki, DO, Main

Line Health, Bryn Mawr

Hospital, 130 S Bryn Mawr

Ave, Bryn Mawr, PA,

19010-3121.

Email: dobrackia@mlhs.org

Submitted

April 26, 2019;

revision received

June 19, 2019;

accepted

June 24, 2019.

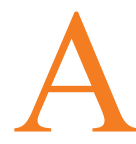

66-year-old man who did not routinely seek medical care presented to the hospital with generalized weakness for 4 days. He described chronic right knee pain. Medical history included untreated rheumatoid arthritis and bilateral knee replacement 16 years prior. On examination, his right knee was fixed at 45-degree flexion. Femoral hardware and pus protruded through hyperemic skin (image A). He and his family claimed the hardware had been exposed for "years," beginning with a small skin opening. Accumulation of detritus material is shown in image $B$.

The clinical findings met the Infectious Disease Society of America's definition of prosthetic joint infection by virtue of the persisting sinus tract. ${ }^{1}$ Plain radiographs were concerning for tibial and femoral osteomyelitis, and there was distal- to midfemoral osteolysis with complete destruction of the femoral metaphysis. Because of the extent of proximal bone involvement and concern for noncompliance if multiphase intervention were pursued, above-the-knee amputation was deemed the most viable option. Although nonsurgical, palliative measures for exposed hardware have been accomplished, ${ }^{2}$ the patient's age and ability to rehabilitate led to this approach. Patients with rheumatoid arthritis have a higher risk of prosthetic joint infection. ${ }^{3}$ Treatment should take into account patient preferences and rehabilitation potential. (doi:10.7556/jaoa.2020.034)

\section{References}

1. Osmon DR, Berbari EF, Berendt AR, et al. Diagnosis and management of prosthetic joint infection: clinical practice guidelines by the Infectious Diseases Society of America. Clin Infect Dis. 2013;56(1):e1-e25. doi:10.1093/cid/cis803

2. Zamani N, Barshes NR. Long-term wound palliation to manage exposed hardware in the setting of peripheral arterial disease. Plast Reconstr Surg Glob Open. 2019;7(2):e2058. doi:10.1097/ GOX.0000000000002058

3. Lenguerrand E, Whitehouse MR, Beswick AD, et al. Risk factors associated with revision for prosthetic joint infection following knee replacement: an observational cohort study from England and Wales. Lancet Infect Dis. 2019;19(6):589-600. doi:10.1016/ S1473-3099(18)30755-2

(c) 2020 American Osteopathic Association
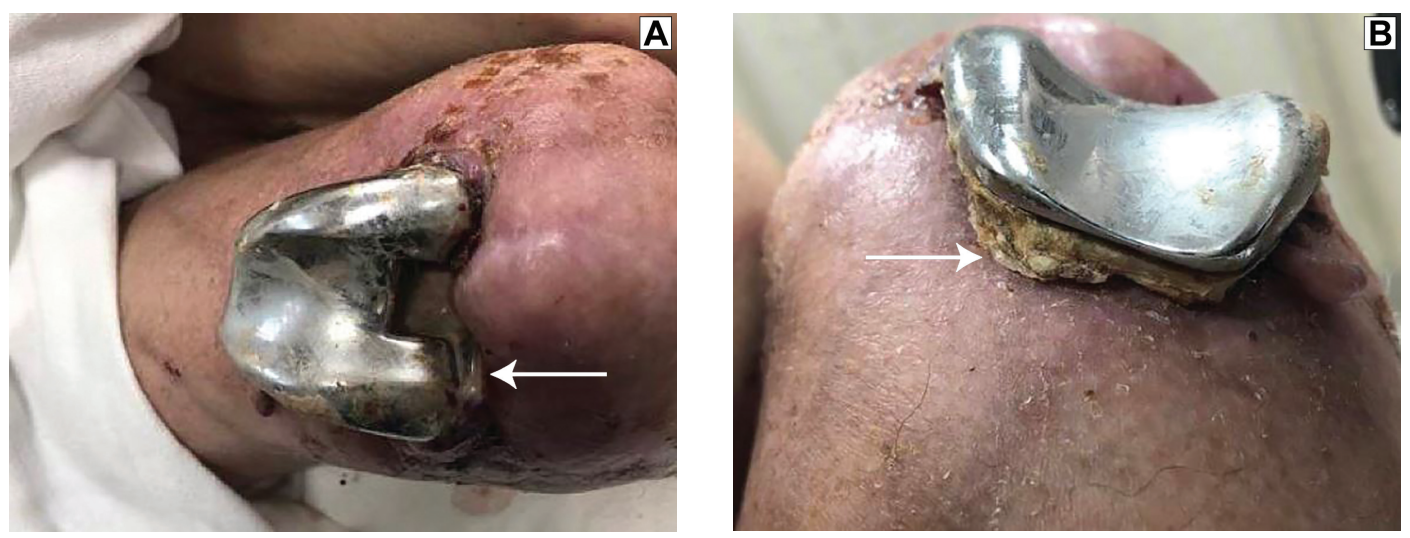